\title{
THE VALIDITY OF AN ADJUSTABLE COMPRESSION VELCRO WRAP FOR THE TREATMENT OF PATIENTS WITH UPPER LIMB LYMPHEDEMA SECONDARY TO BREAST CANCER: A PILOT STUDY
}

Validação de uma vestimenta de contenção para tratamento de linfedema de membro superior secundário ao câncer de mama: estudo piloto

Larissa Louise Campanholi1,2*, Graziele Chiquette Lopes², Fábio Postiglione Mansani ${ }^{1,3}$, Anke Bergmann ${ }^{4}$, Jaqueline Munaretto Timm Baiocchi ${ }^{5}$

\section{ABSTRACT}

Objective: To analyze the efficacy of an adjustable compression Velcro wraps used to reduce limb volume as a form of treatment for upper limb lymphedema secondary to breast cancer. Methods: Women with lymphedema who had already undergone conventional treatment with compression bandaging were included. These patients were recruited through an evaluation in which the manual perimetry was applied using the truncated cone formula, and in which lymphedema were considered as a difference greater than $10 \%$ and/or $200 \mathrm{~mL}$ between the limbs. Patients wore their compression devices daily, taking them off only for a shower. In a period of one month of use, manual lymphatic drainage was not applied. Performing exercises was allowed 3 times a day. Patients returned after one month to have their limb volume reassessed and also to respond to a questionnaire. Results: A total of 9 patients were evaluated, and the median volume difference between the affected limb and the control during the first evaluation was 564.4 (SD=443.2) $\mathrm{mL}$. At the reevaluation, the median difference was 390.6 (SD=306.8) $\mathrm{mL}$. There was a significant difference when comparing the volumes at the evaluation and reevaluation $(p=0.008)$. The degree of satisfaction was $9(S D=1.3)$. Conclusion: The adjustable compression Velcro wrap was effective in the reduction of limb volume in with lymphedema. In addition, the patients reported that the device was more practical and more comfortable compared to the compression bandage. Patients who live in other cities or who are not available to perform daily treatment can benefit from the use of the device.

KEYWORDS: Physiotherapy; lymphedema; breast cancer.

\section{RESUMO}

Objetivo: Analisar a eficácia de uma vestimenta de contenção em velcro para redução do volume do membro como forma de tratamento de linfedema de membro superior secundário ao esvaziamento axilar por câncer de mama. Métodos: Foram incluídas mulheres com linfedema que já tivessem realizado o tratamento convencional com enfaixamento compressivo. O recrutamento dessas pacientes foi através da avaliação com a perimetria manual aplicada na fórmula do cone truncado,

Study carried out at the Instituto Sul Paranaense de Oncologia - Ponta Grossa (PR), Brazil.

${ }^{1}$ Instituto Sul Paranaense de Oncologia - Ponta Grossa (PR), Brazil.

${ }^{2}$ Centro de Ensino Superior dos Campos Gerais - Ponta Grossa (PR), Brazil.

${ }^{3}$ Universidade Estadual de Ponta Grossa - Ponta Grossa (PR), Brazil.

${ }^{4}$ Instituto Nacional do Câncer (INCA) - Rio de Janeiro (RJ), Brazil.

${ }^{5}$ Postgraduate Program at the Fundação Antonio Prudente, A.C. Camargo Cancer Center - São Paulo (SP), Brazil.

*Corresponding author: larissalcm@yahoo.com.br

Conflict of interests: nothing to declare.

Received on: 03/03/2017. Accepted on: 05/29/2017 
considerando linfedema uma diferença maior que $10 \%$ e/ou $200 \mathrm{~mL}$ entre os membros. As pacientes deveriam utilizar diariamente a vestimenta, só retirando para tomar banho. Nesse período de um mês de uso, não deveriam fazer drenagem linfática manual, e sim apenas exercícios linfomiocinéticos três vezes ao dia. As pacientes retornaram após um mês para a reavaliação do volume do membro e também responderam a um questionário. Resultados: Foram avaliadas 9 pacientes, sendo que a mediana de diferença de volume entre o membro afetado e o controle na primeira avaliação foi de 564,4 $(D P=443,2) \mathrm{mL}$. Na reavaliação, a mediana da diferença foi de 390,6 $(D P=306,8) \mathrm{mL}$. Houve diferença significativa quando comparados os volumes na avaliação e na reavaliação $(p=0,008)$. O grau de satisfação da vestimenta foi de $9(D P=1,3)$. Conclusão: A vestimenta mostrou-se eficaz como alternativa na redução do volume do membro com linfedema, e os pacientes relataram ser mais prática e proporcionar maior comodidade quanto comparada ao enfaixamento compressivo. Pacientes que moram em outras cidades ou que não têm disponibilidade para realizar tratamento diariamente podem se beneficiar do uso da vestimenta.

PALAVRAS-CHAVE: Fisioterapia; linfedema; câncer de mama.

\section{INTRODUCTION}

Lymphedema is a potential side effect of oncologic treatment followed by lymph node dissection. It is a chronic, progressive and debilitating pathology and is characterized by the collection of fluid in the interstitial tissues. According to a meta-analysis study, its incidence in cancer survivors is $15 \% .^{1}$

Estimates of the incidence and prevalence of lymphedema related to breast cancer vary considerably in the literature. Factors responsible for this variation include lack of standardized diagnostic criteria, measurement procedures, methodological limitations of studies, variations in populations and postoperative follow-up periods. In general, the prevalence of lymphedema varies between $9 \%$ and $40 \%$, affecting $24-49 \%$ of women after mastectomy, $4-28 \%$ after lumpectomy with axillary dissection and 5-34\% after surgery and radiotherapy. Breast cancer statistics in Brazil reveal that about 3-5 thousand patients with breast cancer will develop lymphedema. ${ }^{2}$

Regarding conservative treatments, complex decongestant physical therapy (CDPT) has been highlighted as the best way to reduce the volume of upper limb lymphedema. The therapy is divided into two phases. The first phase aims at the maximum reduction of limb volume through skin care, manual lymphatic drainage (MLD), physical exercises and inelastic compression bandages. The maintenance phase, or second phase, comes immediately afterwards. It consists of the adaptation of elastic compression stockings, exercises and self-massage, in order to preserve and optimize the results obtained in the initial phase. ${ }^{3}$

Inelastic compression bandaging is one of the main factors responsible for reducing limb volume, but it needs to be performed daily or every other day for the pressure to be within the expected range. However, patients with limb bandages have difficulties bathing and performing activities of daily living. It is believed that by replacing the bandage with an easy-to-wear wrap with ideal compression, the patient's life would be made easier. In the world literature, there is little information on the use of alternative devices for compressive bandaging for the treatment of lymphedema. Patients who live far from health centers or who lack the time needed to undergo daily physical therapy treatment can benefit from the use of the compression wrap, since it is much faster and more practical than conventional compression bandaging. Therapies that use simple application methods, such as compression wraps, are extremely valuable, due to the chronicity of lymphedema. The wrap is a simple solution that seeks to reduce costs, treatment time, and the number of doctor visits, which facilitates self-care and provides greater patient independence. ${ }^{4}$

The objective of this study was to analyze the validity and efficacy of an inelastic Velcro wrap for the treatment of upper limb lymphedema in patients with lymphedema secondary to breast cancer. The limb was assessed by manual perimetry and the volume was calculated in milliliters $(\mathrm{mL})$ using the truncated cone formula. We sought to describe the benefits or harms related to the use of adjustable compression Velcro wraps as a substitute for the traditional compression bandaging.

\section{METHODS}

We performed a prospective, descriptive cross-sectional study. Patients were selected for convenience. This study was approved by the Ethics Committee, and each patient signed an informed consent form. Patients were also requested to sign an authorization for image, interview and questionnaire use.

We included women with upper limb lymphedema who underwent axillary lymph node dissection for the treatment 
of breast cancer and who had already undergone conventional CDPT treatment with compressive bandaging.

Patients with primary or bilateral lymphedema and with perimetry within the normality value (less than $10 \%$ and/or 200 $\mathrm{mL}$ of difference in volume between affected and control limbs) were excluded, as well as individuals with a postoperative period of less than six months.

Lymphedema was assessed by manual perimetry before and after the compression wrap. A physical examination by palpation was performed to verify the presence of fibrosis and a Godet sign. Oncology clinical data were obtained from the available medical records at the institution.

Perimetry was performed with a flexible tape measure, starting from the intra-articular line of the elbow, measured superiorly and inferiorly every $7 \mathrm{~cm}(7,14$ and $21 \mathrm{~cm})$. The evaluation was performed bilaterally for the comparison of the affected limb with the unaffected limb (control), during which the patient should be naked, seated, and with limbs relaxed and supported on a table. Measurements of the manual perimetry were applied in the truncated cone Equation 1 to obtain the limb volume:

$$
\mathrm{V}=\mathrm{h}\left(\mathrm{C} 1^{2}+\mathrm{C} 1 \times \mathrm{C} 2+\mathrm{C} 2^{2}\right)
$$

$12 \pi$

In which:

$\mathrm{V}=$ final volume of the limb segment;

$\mathrm{C} 1$ and $\mathrm{C} 2$ = circumferences between the measured points; $\mathrm{h}=$ distance between the circumferences $(\mathrm{C} 1$ and $\mathrm{C} 2$ in each segment), all calculated in centimeters.

A volume difference greater than $10 \%$ and/or $200 \mathrm{ml}$ between the upper limbs was considered lymphedema. The degree of upper-limb lymphedema was classified according to Stillwell et al. (1969), quoted by Vries et al. ${ }^{4}$, into: 0.0-10.0\% insignificant; $10.1-20.0 \%$ slight; $20.1-40.0 \%$ moderate; $40.1-80.0 \%$ marked and $>80.1 \%$ severe.

In the first appointment, patients received a questionnaire asking socio-demographic information and a form with instructions on how to use the compression wrap. Patients also received a diary to keep daily and weekly records of complaints and sensations perceived, as well as the amount of time of daily use (day and night). Patients were then instructed to wear the wrap most of the time - including at bedtime - and should only remove it when bathing or to wash it. They were also instructed to adjust the wrap every time they felt it becoming loose, and to check it every two hours.

The self-adjusting Velcro compression wrap is made of a type of rubber whose base composition is polychloropene, a synthetic elastomeric polymer of chloropene. On one side the rubber is coated with polyamide and, on the other, it is coated with $100 \%$ polyester plush. The correct way to wear the glove accompanying the compression wrap is shown in Figure 1.
Patients were advised not to undergo MLD during the time they were wearing the wrap, but were instructed to do exercises three times a day to improve lymphatic system function. Exercises included finger flexion and extension, hand flexion and extension, radial and ulnar deviation, wrist flexion and extension, elbow flexion and extension, pronation and supination of the hand, shoulder rotation, pulley, finger ladder and skin care. Patients received printed guidelines for the exercises.

After a month, they returned to have their limb volume reassessed through manual perimetry and they also answered a questionnaire containing information such as degree of satisfaction with the compression wrap in relation to traditional dressings, time of use, pros and cons, etc.

The study population was characterized by descriptive statistics (mean, median, standard deviation, maximum and minimum values and percentage). Adherence to normality was verified using Kolmogorov-Smirnoy and Shapiro-Wilk tests. We assumed a significance level of $5 \%$ for all statistical tests. Statistical analysis of limb volume differences before and after the use of the wrap was performed through univariate analysis using the Wilcoxon test. Statistical analyses were performed using SPSS 20.0 for Windows.

\section{RESULTS}

Ten women with upper limb lymphedema resulting from axillary lymph node dissection as a treatment for breast cancer participated in the study. However, the sample was composed of
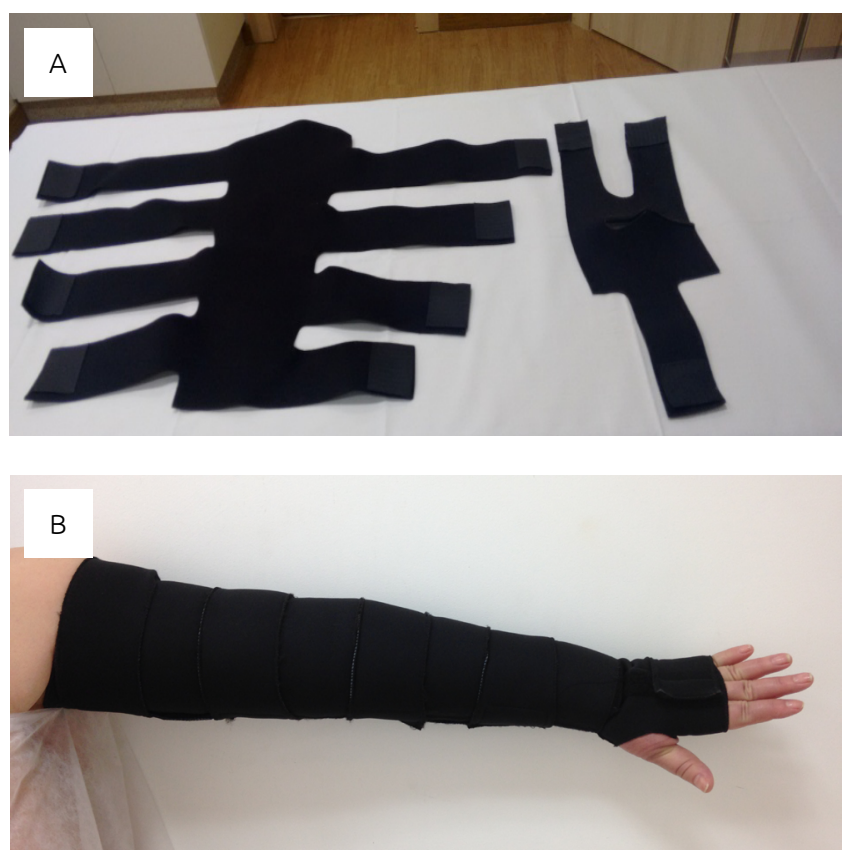

Figure 1. (A) Self-adjustable compression (Velcro) wrap for upper limb volume reduction in lymphedema; (B) instructions on how to use glove and compression wrap for the treatment of upper limb lymphedema. 
nine patients since one of them used the compression wrap for only one day and refused to continue the treatment, claiming that she had difficulty putting on the device by herself. The mean age of the 9 participants was 58.6 years ( $S D=11.6$ ), with a minimum age of 41 and a maximum age of 82 . The mean body mass index (BMI) was 30.8 (SD=5.1), ranging from 22.0-39.5.

Regarding cancer staging, $44.4 \%(\mathrm{n}=4)$ were stage II and 55.6\% $(n=5)$, stage III. All patients underwent axillary lymph node dissection and modified radical mastectomy, in addition to chemotherapy. Only one patient (11.1\%) was treated with neoadjuvant chemotherapy. The other patients were treated with adjuvant therapy. However, $77.8 \%(\mathrm{n}=7)$ underwent radiotherapy and $44.4 \%(\mathrm{n}=4)$ underwent hormone therapy - tamoxifen (66.7\%) and anastrosole $(22.2 \%)$.

Eight patients were white (88.9\%) and one was black, $55.6 \%$ were married, $33.3 \%$ were divorced and $11.1 \%$ were single. Regarding education, $22.2 \%(\mathrm{n}=2)$ had a postgraduate diploma, $22.2 \%(\mathrm{n}=2)$ had an undergraduate diploma, $22.2 \%(\mathrm{n}=2)$ had incomplete higher education, $22.2 \%(\mathrm{n}=2)$ had incomplete secondary education and $11.1 \%(\mathrm{n}=1)$ had complete secondary education. We observed that patients with a lower level of education had more difficulty answering the questions on the daily and weekly questionnaires.

All patients were right-handed and lymphedema was more common on the left side $(55.6 \%, \mathrm{n}=5)$. The mean postoperative time was 93.4 months $(\mathrm{SD}=28.1)$ and the mean time interval between surgery and the onset of lymphedema was 27.5 months (SD 14.0). Numerical variables are shown in Table 1.
The median volume difference between the affected limb and the control at the first assessment was $564.4 \mathrm{~mL}$ (SD=443.2). In the last measurement, the median difference was $390.6 \mathrm{~mL}$ (SD 306.8). We observed a statistically significant difference when comparing the volumes in the first and last measurements $(\mathrm{p}=0.008)$ (Table 2).

Decreased limb volume meant that the degree of lymphedema was also modified. Most of the patients underwent stage reduction. Initially, $55.6 \%$ of the patients had mild lymphedema $(n=5), 22.2 \%$ had moderate lymphedema $(n=2)$ and $22.2 \%$ had marked lymphedema $(\mathrm{n}=2)$. After the intervention, $33.3 \%$ of the patients were below $10 \%(n=3)-$ that is, within the normal range,$- 44.4 \%$ presented mild lymphedema $(n=4)$ and $22.2 \%$, moderate.

Figure 2 shows the beginning and end of treatment in one of the patients, in which marked lymphedema was reduced to moderate. The right upper limb had a volume of $3645.6 \mathrm{~mL}$, compared to $2807.8 \mathrm{~mL}$ after the application of the compression wrap.

The most frequent complication in the postoperative period was seroma, which occurred in $44.4 \%$ of the cases $(n=4)$, followed by cicatricial dehiscence and infection, both in $11.1 \%$ of the patients $(\mathrm{n}=1)$. The 7 patients who underwent radiation therapy $(77.7 \%)$ had radiodermatitis in $28.6 \%$ of the cases $(\mathrm{n}=2)$. Erysipelas occurred in $22.2 \%$ of cases $(n=2)$.

The main treatments previously given to the patients included MLD, compression bandaging, skin care, exercises and use of elastic sleeves in all cases. Also, $44.4 \%$ of patients used kinesio taping. None of the patients used laser or pneumatic compression.

Table 1. Numerical variables of patients with upper limb lymphedema.

\begin{tabular}{|c|c|c|c|c|c|}
\hline Numerical variables & Mean & Median & SD & Minimum & Maximum \\
\hline Age & 58.56 & 57.00 & 11.62 & 41.00 & 82.00 \\
\hline BMI & 29.69 & 30.80 & 5.15 & 22.00 & 39.50 \\
\hline Surgery time (months) & 93.44 & 75.00 & 42.38 & 55.00 & 162.00 \\
\hline Lymphedema time (months) & 65.89 & 51.00 & 44.39 & 6.00 & 130.00 \\
\hline Time between surgery and lymphedema onset (months) & 27.56 & 24.00 & 14.0 & 13.00 & 49.00 \\
\hline Number of positive lymph nodes & 2.78 & 3.00 & 2.82 & 0.00 & 8.00 \\
\hline Number of dissected lymph nodes & 18.33 & 16.00 & 5.74 & 13.00 & 32.00 \\
\hline Wrap time use per day (hours) & 19.40 & 21.00 & 4.05 & 14.00 & 23.00 \\
\hline
\end{tabular}

BMI: body mass index; SD: standard deviation.

Table 2. Volume difference between affected limb and control limb before and after the compression wrap in patients with upper limb lymphedema.

\begin{tabular}{|c|c|c|c|c|c|c|}
\hline Numerical variables & Mean & Median & SD & Minimum & Maximum & P-value* \\
\hline Volume difference before (mL) & 643.48 & 564.40 & 443.16 & 214.00 & 1587.90 & \multirow{2}{*}{0.008} \\
\hline Volume difference after (mL) & 375.93 & 390.60 & 306.79 & 29.30 & 865.60 & \\
\hline Volume difference before (\%) & 21.67 & 18.60 & 12.34 & 10.30 & 43.60 & \multirow{2}{*}{0.008} \\
\hline Volume difference after (\%) & 13.38 & 13.10 & 10.76 & 1.20 & 30.20 & \\
\hline
\end{tabular}

SD: standard deviation *Wilcoxon test 
Fibrosis remained both before and after the use of the compression wrap, that is, the containment device did not promote fibrosis improvement nor did it reduce the Godet sign. However, the use of the wrap importantly impacted the sensation of heaviness and limb volume increase, as shown in Table 3. Before wearing the wrap, $88.9 \%$ of the patients reported experiencing a sensation of heaviness, which was reduced to $11.1 \%$ after use. All patients reported reduced limb volume and $88.9 \%$ felt more protected when wearing the compression wrap. Patients complained that the Velcro got loosened and grabbed onto their

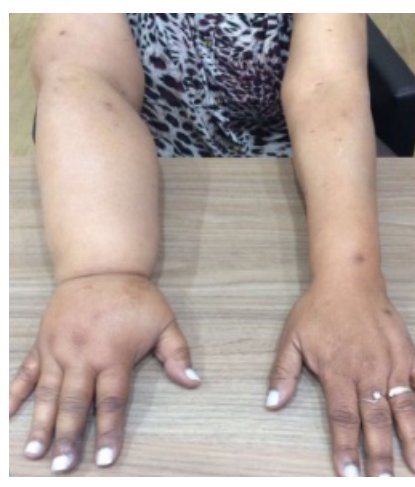

Day 0

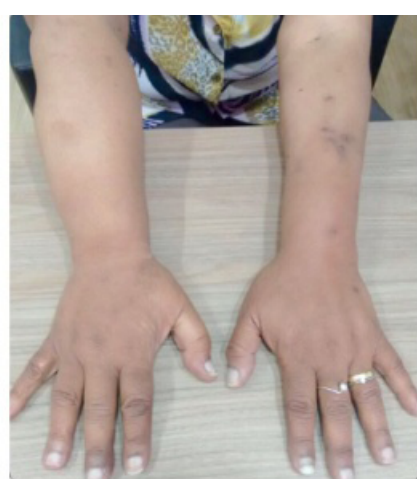

Day 30
Figure 2. Initial assessment (day 0) prior to treatment; Reassessment (day 30) after the use of the Velcro wrap. A reduction from marked to moderate lymphedema can be observed.

Table 3. Evaluation of the complaints, sensations and possible complications perceived by patients during the period of use of the compression wrap

\begin{tabular}{l|l|c}
$\begin{array}{l}\text { Complaints, sensations and complications } \\
\text { during the use of the compression wrap }\end{array}$ & $\mathbf{n}$ & $\%$ \\
\hline Fibrosis before & 3 & 33.3 \\
\hline Fibrosis after & 3 & 33.3 \\
\hline Godet sign before & 3 & 33.3 \\
\hline Godet sign after & 3 & 33.3 \\
\hline Sensation of heaviness before & 8 & 88.9 \\
\hline Sensation of heaviness after & 1 & 11.1 \\
\hline Volume increase before & 9 & 100 \\
\hline Volume increase after & 5 & 55.6 \\
\hline Arm discomfort & 5 & 55.6 \\
\hline Arm tightening & 4 & 44.4 \\
\hline Stopped going out because of the wrap & 2 & 22.2 \\
\hline Felt protected wearing the wrap & 8 & 88.9 \\
\hline Felt insecure wearing the wrap & 2 & 22.2 \\
\hline Reported difficulty wearing the wrap & 5 & 55.6 \\
\hline Limb weight decreased & 8 & 88.9 \\
\hline Limb size decreased & 9 & 100 \\
\hline Wrap came off & 9 & 100 \\
\hline
\end{tabular}

clothes. They also reported that their arms sweated a lot during the exercises, and it was necessary to reset the device every two or three hours, because it would slip and get loose.

The mean patient satisfaction level was 9 (SD 1.3), on a scale ranging from $0-10$, with 7 being the minimum value and 10 being the maximum value attributed by the patient. All patients evaluated the wrap as a better option in relation to conventional compression bandages in that it was more practical and convenient.

\section{DISCUSSION}

Although the literature shows a consensus about compression bandaging as a crucial part of lymphedema treatment, patients have difficulty self-bandaging their arms, especially those who lack access to physiotherapy with the necessary frequency. The purpose of the compression wrap is to enable these patients to correctly use the device as an auxiliary form to treat lymphedema with satisfactory results.

This pilot study sought to analyze the benefits and possible harms caused by compression wraps. After one month, the Velcro and the tissue were slightly damaged due to constant use, and patients expressed discomfort about the heat. New materials should be looked into for more durable and fresher wraps.

Late-onset lymphedema is more difficult to treat than initial lymphedema. Although the patients had lymphedema for an average of 5 years, we observed a significant limb volume reduction.

In a study of 1,054 women with breast cancer undergoing axillary lymph node dissection, the incidence of lymphedema was $17 \%$ at 2 years postoperatively, and $30 \%$ at 5 years. ${ }^{6}$ The mean rate of appearance of lymphedema in the present sample was 2 years, and the later case was 4 years postoperatively.

Oremus et al. systematically reviewed secondary lymphedema cases and observed that most authors considered lymphedemas after more than 6 months postoperatively. ${ }^{7}$ When analyzing the diagnostic of lymphedema, most of the studies considered differences between homolateral and contralateral limbs above $10 \%$ and/or $200 \mathrm{~mL}$, as was proposed in the present study.

Since lymphedema is a chronic lymphatic disorder, patients require prolonged physiotherapeutic follow-up. Patients often take part in the first phase of the CDPT, but they end up neglecting the second phase, in which limb volume can increase again. The patients studied had previously undergone a CDPT and, although they were in the maintenance phase, they had significant increase in limb volume (more than $10 \%$ or $200 \mathrm{~mL}$ of difference compared to the contralateral arm).

Vignes et al. conducted a study of 682 patients with lymphedema to check limb volume control during the maintenance phase, observing a better response in subjects who used daytime elastic and inelastic compression bandages at bedtime. ${ }^{8}$ Therefore, we suggest that the Velcro wrap proposed in our study may also be used as a form of nocturnal inelastic compression 
bandaging, contributing to both edema reduction and maintenance phases.

All patients should have previously received compression therapy to enable a comparison with the wrap. However, a study showed that the most used technique in the treatment of upper and lower limb lymphedema was isolated MLD and that bandaging was performed in only $18 \%$ of cases. ${ }^{9}$ In the present sample, MLD was not performed, demonstrating that this technique is not the most important in limb volume reduction, but rather the combination of inelastic compression with exercises.

A pilot study published in 2016 sought to record the performance of a compression wrap in 17 patients with lymphedema or venous ulcers who used a contention device as a self-care option in the treatment and maintenance of lower limb edema. Patients with lymphedema were also treated with MLD and received guidelines regarding skin care. They observed a reduction in limb circumference, demonstrating that the adjustable Velcro compression wrap may provide a simple, clinically effective and patient-acceptable solution for self-care with compression. ${ }^{4}$

Another analysis was performed in 30 individuals with moderate to severe lower-limb lymphedema, divided into two groups: one wearing compression wraps and another wearing multilayer inelastic compression bandages. It was observed that the wrap was associated with greater reduction in limb volume after 24 hours compared with compression bandaging. As in the methodology proposed here, patients were able to self-apply the device after receiving instructions on how to use it and set the correct compression rate every 2 hours. ${ }^{10}$

Mosti et al. compared the efficacy and comfort of compression wraps and compression bandaging and they found that wrap devices are effective and well tolerated not only during maintenance therapy, but also in the initial decongestant treatment phase of patients with lower limb venous edema. ${ }^{11}$

A literature review of the use of compression wraps has shown that most studies investigated lower limb lymphedema. There is little scientific evidence for the use of adjustable compression devices in patients with lymphedema, considering that most of the evidence is in the form of descriptive works, case studies or relatively small research studies. These studies are performed over a short period of time and do not reflect the long-term nature of these chronic conditions and their treatment. However, there is clinical evidence that compression wrap devices improve the quality of life and independence of patients. ${ }^{12}$

Although infection is a significant risk factor for lymphedema, ${ }^{13}$ patients in this study reported low rates of postoperative infection and erysipelas, probably due to the small sample size. Radiation therapy is also a risk factor, as it promotes the formation of tissue fibrosis, with consequent lymphatic vasoconstriction, significant damage to the lymph node filtration function and altered immune response. Lymphatic anastomoses are still impaired by cicatricial fibrosis. ${ }^{14}$ We observed that more than half of the patients required radiotherapy as a complementary treatment.

It is common patients have symptoms such as a sensation of heaviness, pain and discomfort, which significantly reduces their physical function, mobility and ability to perform daily activities, consequently worsening their quality of life. Psychological and emotional concerns are also present. Patients commonly report increased levels of distress and a feeling of helplessness, a fear of a possible disease progression and adverse changes in body image and self-esteem. ${ }^{15,16} \mathrm{~A}$ sensation of heaviness occurred in $88.9 \%$ of the patients before the compression wrap. However, after its use, only $11.1 \%$ of these patients mentioned the discomfort. Campanholi et al. ${ }^{17}$ observed good agreement between manual perimetry and subjective evaluation through self-report of heaviness and/or upper limb swelling. When limb perimetry decreases, sensation of heaviness is reduced.

Interstitial plasma protein accumulation and insufficient proteolytic activity promote angiogenesis with neovascularization and fibrosis, impeding lymphedema regression. ${ }^{18}$ Fibroses intensify lymphatic system lesions, damaging the flow of interstitial fluid and avoiding lymphatic reabsorption. ${ }^{19}$ Compression wraps showed no interference with fibrosis, since the patients who had fibrosis, continued to have it even after the use of the compression device. We emphasize the necessity to wear the compression wrap in association with physiotherapeutic treatment that treats the fibrosis through specific manual therapy, in order to provide a greater decrease in the limb volume.

Just as Ehmann et al. cite that more studies with the contention device should be done, we believe that there is a need for studies mainly for upper limb lymphedema, since most of those found in the literature focused only on lower limbs. ${ }^{5}$

\section{CONCLUSION}

Adjustable compression Velcro wrap is an interesting method for upper limb volume reduction in patients with lymphedema, since there was a significant limb volume difference before and after the use of the device.

We believe that compression wraps can be considered an alternative method for reducing limb volume in patients with lymphedema. Based on patients' comments, they considered the compression wrap was better, more practical and more comfortable when compared to compression bandaging. 


\section{REFERENCES}

1. Cormier JN, Rourke L, Crosby M, Chang D, Armer J. The surgical treatment of lymphedema: a systematic review of the contemporary literature (2004-2010). Ann Surg Oncol. 2012;19(2):642-51.

2. Bevilacqua JLB, Bergmann A, Andrade MF. Linfedema após o câncer de mama - da epidemiologia ao tratamento. Rev Bras Mastologia. 2008;18(4):171-8.

3. Lanza M, Bergmann A, Ferreira MGCL, de Aguiar SS, Dias RA, Abrahão KS, et al. Quality of Life and Volume Reduction in Women with Secondary Lymphoedema Related to Breast Cancer. Int J Breast Cancer. 2015. doi: 10.1155/2015/586827.

4. Vries M, Vonkeman WG, Ginkel RJ, Hoeskstra HJ. Morbidity after axillary sentinel lymph node biopsy in patients with cutaneous melanoma. Eur J Surg Oncol. 2005;31:778-83.

5. Ehmann S, Whitaker JC, Hampton S, Collarte A. Multinational, pilot audit of a Velcro adjustable compression wrap system for venous and lymphatic conditions. J Wound Care. 2016;25(9):513-20.

6. Bevilacqua JL, Kattan MW, Changhong Y, Koifman S, Mattos IE, Koifman RJ, et al. Nomograms for Predicting the Risk of Arm Lymphedema after Axillary Dissection in Breast Cancer. Ann Surg Oncol. 2012;19:2580-9.

7. Oremus M, Dayes I, Walker K, Raina P. Systematic review: conservative treatments for secondary lymphedema. BMC Cancer. 2012;12:6. doi: 10.1186/1471-2407-12-6.

8. Vignes S, Porcher R, Arrault M, Dupuy A. Factors influencing breast cancer-related lymphedema volume after intensive decongestive physiotherapy. Support Care Cancer. 2011;19:935-40.

9. Campanholi LL, Duprat Neto JP, Fregnani JHTG. Analysis of physical therapy in patients who had radical lymphadenectomy for cutaneous melanoma. Applied Cancer Research. 2012;32(1):12-5.

10. Damstra RJ, Partsch H. Prospective, randomized, controlled trial comparing the effectiveness of adjustable compression Velcro wraps versus inelastic multicomponent compression bandages in the initial treatment of leg lymphedema. J Vasc Surg Venous Lymphat Disord. 2013;1(1):13-9.

11. Mosti G, Cavezzi A, Partsch H, Urso S, Campana F. Adjustable Velcro Compression Devices are More Effective than Inelastic Bandages in Reducing Venous Edema in the Initial Treatment Phase: A Randomized Controlled Trial. Eur J Vasc Endovasc Surg. 2015;50(3):368-74.

12. Williams A. A review of the evidence for adjustable compression wrap devices. J Wound Care. 2016;25(5):242-7.

13. Campanholi LL, Duprat NetoJP, FregnaniJHTG. Mathematical model to predict risk for lymphoedema after treatment of cutaneous melanoma. Int J Surg. 2011;9:306-9.

14. Dunberger G, Lindquist H, Waldenstrõm AC, Nyberg T, Steineck G, Avall-Lundqv. Lower limb lymphedema in gynecological cancer survivors--effect on daily life functioning. Support Care Cancer. 2013;21(11):3063-70.

15. Finnane A, Lui Y, Battistura D, Jansa M, Hayes SC. Lymphedema after breast or gynecological cancer: use and effectiveness of mainstream and complementary therapies. J Altern Complement Med. 2011;17(9):867-9.

16. Kim SJ, Park YD. Effects of complex decongestive physiotherapy on the oedema and the quality of life of lower unilateral lymphoedema following treatment for gynecological cancer. Eur J Cancer Care. 2008;17(5):463-8.

17. Campanholi LL, Duprat Neto JP, Fregnani JHTG. Evaluation of inter-rater reliability of subjective and objective criteria for diagnosis of lymphedema in upper and lower limbs. J Vasc Bras. 2015;14(1):16-21.

18. Djavanmard MP, Michl I, Korpan M, Fazeny B, Budinsky AC, Wiesinger E, et al. Impaired hemorheology in patients with postmastectomy lymphedema. Breast Cancer Res Treat. 1996;38:283-8.

19. Wiig H, Keskin D, Kalluri R. Interaction between the extracellular matrix and lymphatics: consequences for lymphangiogenesis and lymphatic function. Matrix Biol. 2010;29(8):645-56. 